\section{PACHYONYCHIA CONGENITA IN THE SLOVENIAN POPULATION}

Kansky' ${ }^{1}$ P., Bowden ${ }^{2}$, D., Rems ${ }^{3}$ and V. Dragoš1 ${ }^{1}$.

In Slovenia hereditary disorders of keratinization are rather frequent, more than 250 cases of various types of hereditary palmoplantar keratodermas are known. At least 12 cases of pachyonychia congenita type JadassohnLewandowsky (PC-1) have been diagnosed clinically, while the type Jackson-Lowler (PC-2) has not been observed. According to the data in the literature mutations in keratins $\mathrm{K} 6$ and $\mathrm{K} 16$ were reported in $\mathrm{PC}-1$ and of keratin $\mathrm{KI} 7$ in PC-2.

Symptoms characterizing PC-I: a substantially thickened and brown nail plate, usually affecting all fingers and the majority of toes; insular hyperkeratoses of varying degree on pals and soles; follicular hyperkeratoses mostly on the temples and extensor surfaces of arms. leukokeratosis of the tongue and buccal mucosa.

PC-2 patients usually have milder symptoms, they lack oral involvement, but natal teeth and cutaueous cysts can be expressed.

In 8 of our patients mutations have been confirmed by molecular analysis of the DNA. In 5 of these, members of families $A$ and $O$, identical deletion mutations of one codon in the 1A Central Rod Domain (helix) of K6a were identified: removal of one of two adjacent asparagine N170/171 in exon 1 . In two patients belonging to family $\mathrm{P}$ a F174S mutation (phenylalanine to serine) and in the patient DL N171K (asparagine to lysine) mutation were detected. Two patients did not follow our invitation for a detailed investigation, in one patient such the DNA analysis is in course, while in 1 no mutation in keratins $\mathrm{K} 6 \mathrm{a}, \mathrm{Kl} 6$ and $\mathrm{K} 17$ were observed.

Departments of Dermatology Medical Center Ljubljana', UWCM Cardiff $\mathrm{UK}^{2}$ and Maribor Teaching Hospital ${ }^{3}$

\section{ANALYSIS OF HIP JOINT ARTICULAR LAYER THICKNESS IN RELATION TO COXARTHROSIS}

Boštjan Kersnič ${ }^{1}$, Dragica Smrke ${ }^{1}$, Veronika Kralj-Iglič ${ }^{2}$, Aleš Iglič ${ }^{3}$

Studies in orthopaedic literature have shown that incidence of coxarthrosis is greater in female population and several factors are already known that can influence the development of coxarthrosis. Some of these factors are geometrical and biomechanical factors defining the status of the hip joint the gender, obesity etc. Degenerative disease of the hip joint is usually characterised by narrowing of superior portion of the hip joint - the weightbearing area, but there are also other radiological signs. The average thickness of the hip joint articular layer could also influence the development of such degenerative diseases, but has not been studied until present.

Standard anterior-posterior radiographs for 79 healthy female and 21 healthy male subjects were processed by computer-aided system in order to determine this geometrical parameter. Acetabular and femoral head radiuses were calculated using optimisation method with the least-square method. The average hip joint articular layer thickness was estimated to be the difference between these two parameters. Our findings show that the average value of the hip joint articular layer thickness is smaller in the female population, which has not been reported in similar studies.

${ }^{1}$ Clinical department of Traumatology, Zaloška 2, SI-1000 Ljubljana, Slovenia; ${ }^{2}$ Institute of Biophysics, Medical Faculty, Lipičeva 2, SI-1000 Ljubljana, Slovenia; ${ }^{3}$ Faculty of Electrical Engineering, Tržaška 25, SI1000 Ljubljana, Slovenia; bostjan.kersnic@mf.uni-lj.si

\title{
Topic: Special
}

\section{BIOLOGICAL WORLDS ON THE INTERNET IN VIRTUAL REALITY AND EDUCATIONAL AID}

Tomaž Amon and Vojko Valenčič

When one completes a scientific investigation he typically gets a spreadsheet of numbers. Of course he has to draw a graph in order to understand it. The best way is to use modem computer techniques and produce multimedial visualizations which tell us as much as possible about the data acquired so hard. Then it is much easier to obtain new ideas and scientific hypothesis for the future experiments. For example let's look at the integration of the membrane potentials on a nerve ceII. The presynaptic fibers excite the cell and the sum of their postsynaptic potentials (PSPs) regulates the output of the nerve cell. If you have got the input data it is very difficult to understand the functional model produced by a computer without a proper visualization interface - for example a three dimensional model of a the modelled nerve cell in blue colour, where the intensities of the depolarizations of the membrane at different spots are coded with different intensities of the yellow colour.

VRML (Virtual Reality Modelling Language) represents a fully interactive learning environment in the virtual 3D space. The VRML environment lets you not only to observe a "movie", you can also "step" into it and travel in its virtual space according to your own will. This is enabled by the VRML documents, which establish the virtual reality space on your own computer. The three dimensional world offered by the VRML is not only a luxus. We all are used to live in our three dimensional homes. One understands things better if he imagines them in space. So when one moves in the virtual space that shows the simplified interior of a living cell, he learns about the structures and functions of the cell organelles more realistically as if he only observed a two dimensional picture. In addition we also impement the dynamic simulation of the processes and listens to the sound which makes the associations even stronger.

One of the first attempts to apply VRML on the field of biology is performed by our group visualizing the elementary structures and functions of the living cells. Some of these worlds can also be seen in the internet at:

tomaz.amon@siol.net; vojko@.fe.uni-1j.si; http:/lane.fe.uni-lj.si/-tomaz/VRML 